Fundamental Structural Analysis 
By the same author

Microcomputer Applications in Structural Engineering (with W. H. Mosley)

Other Macmillan titles of related interest

An Introduction to Engineering Fluid Mechanics

J. A. Fox

Polymer Materials: An Introduction for Technologists and Scientists

Christopher Hall

Prestressed Concrete Design by Computer

R. Hulse and W. H. Mosley

Reinforced Concrete Design by Computer

R. Hulse and W. H. Mosley

Civil Engineering Materials, third edition

edited by $\mathrm{N}$. Jackson

Reinforced Concrete Design, third edition

W. H. Mosley and J. H. Bungey

Strength of Materials, third edition

G. H. Ryder

Surveying for Engineers

J. Uren and W. F. Price 


\title{
Fundamental Structural Analysis
}

\author{
W. J. Spencer \\ Department of Civil Engineering, \\ Swinburne Institute of Technology, \\ Hawthorn, Victoria, Australia
}

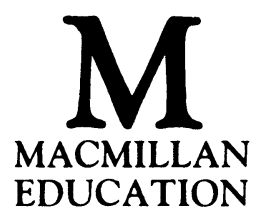


All rights reserved. No reproduction, copy or transmission of this publication may be made without written permission.

No paragraph of this publication may be reproduced, copied or transmitted save with written permission or in accordance with the provisions of the Copyright Act 1956 (as amended), or under the terms of any licence permitting limited copying issued by the Copyright Licensing Agency, 33-4 Alfred Place, London WC1E 7DP.

Any person who does any unauthorised act in relation to this publication may be liable to criminal prosecution and civil claims for damages.

First published 1988

Published by

MACMILLAN EDUCATION LTD

Houndmills, Basingstoke, Hampshire RG21 2XS and London

Companies and representatives throughout the world

British Library Cataloguing in Publication Data

Spencer, W. J.

Fundamental structural analysis.

1. Structures, Theory of

I. Title

624.1'71 TA645

ISBN 978-0-333-43468-0

DOI $10.1007 / 978-1-349-19582-4$

ISBN 978-1-349-19582-4 (eBook)

Diskette copies of 'MATOP' for IBM and IBM-compatible machines are available from the author, from whom further details can be obtained on request. Please address enquiries to:

\author{
Dr W. J. Spencer \\ Department of Civil Engineering \\ Swinburne Institute of Technology \\ P.O. Box 218 \\ Hawthorn, Victoria 3122 \\ Australia
}




\section{Contents}

List of Examples $\quad$ xi

$\begin{array}{ll}\text { Preface } & \text { xiii }\end{array}$

1 Introduction to Structural Engineering 1

$\begin{array}{lll}1.1 & \text { The Nature of Structures } & 1\end{array}$

1.2 Equilibrium and Compatibility 4

1.3 Stress-Strain Relationships and Boundary Conditions 4

1.4 Structural Analysis-An Illustrative Example 5

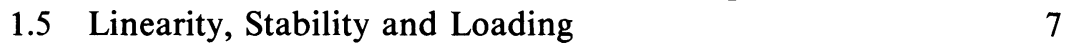

$\begin{array}{lll}\text { 1.5.1 Geometric Non-linearity } & 8\end{array}$

1.5.2 The Stability of Structures 9

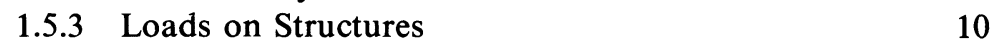

1.6 Scope of the Book-Fundamental Assumptions 11

$\begin{array}{lll}\text { 1.6.1 Sign Conventions } & 11\end{array}$

$\begin{array}{ll}\text { Further Reading } & 12\end{array}$

2 Equilibrium Analysis and Determinacy of Structures 13

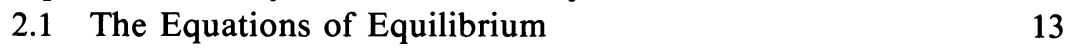

2.1.1 Moment of a Force about an Axis $\quad 14$

2.1.2 Sufficiency of Restraint $\quad 15$

2.1.3 Determinacy of the Basis of Equilibrium 20

$\begin{array}{ll}2.2 \text { A Classification of Structures } & 20\end{array}$

$\begin{array}{lll}2.2 .1 & \text { Skeletal Frames } & 21\end{array}$

2.3 Internal Actions in Structures $\quad 21$

2.4 Statical Determinacy 22

2.4.1 Equations of Condition 24

2.4.2 Degree of Statical Indeterminacy 25 
2.5 Kinematic Determinacy 27

$\begin{array}{lll}2.5 .1 & \text { Degrees of Freedom } & 28\end{array}$

2.5.2 Nodal Degrees of Freedom 28

2.5.3 Structure Degrees of Freedom 29

2.6 Analysis of Statically Determinate Beams and Frames 30

2.7 Analysis of Statically Determinate Trusses 36

2.8 Problems for Solution $\quad 41$

Further Reading $\quad 43$

3 Basic Concepts of the Stiffness Method 44

3.1 Element and Structure Stiffness 45

3.2 Forming the Structure Stiffness Matrix by Direct

3.3 Solution to Obtain Displacements $\quad 51$

3.4 Nature of the Structure Stiffness Matrix 53

3.5 Development of the Slope-Deflection Equations 57

3.5.1 The Moment-Area Theorems 58

3.5.2 The Beam Element Stiffness Matrix 61

3.6 Application to Some Simple Beam Problems 65

3.7 Standard Solutions to Beam Problems 69

$\begin{array}{lll}3.8 & \text { Problems for Solution } & 71\end{array}$

4 The Matrix Stiffness Method-Part 1: Beams and Rectangular Frames $\quad 72$

4.1 The Analysis of Continuous Beams $\quad 72$

4.11 Forming the Structure Stiffness Matrix 72

4.1.2 Solving for Displacements $\quad 76$

4.1.3 Element Actions $\quad 77$

4.1.4 Consideration of Transverse Loads 77

4.2 The Analysis of Rectangular Frames 87

4.2.1 The Column Element Stiffness Matrix 88

4.2.2 Assembly of the Structure Stiffness Matrix 89

4.3 The Direct Stiffness Method 101

4.4 Modification to Element Stiffness Matrices for End Moment Release $\quad 106$

4.5 Application of the Stiffness Method to Beams and Rectangular Frames

$\begin{array}{ll}\text { 4.6 Problems for Solution } & 117\end{array}$

5 The Moment Distribution Method 119

5.1 An Iterative Solution to a Set of Simultaneous Equations 119

5.2 The Elements of the Moment Distribution Method 122

5.3 Application of the Moment Distribution Method 125

5.3.1 Modification for Pin-ended Elements 131 
5.4 Moment Distribution applied to Swaying Rectangular Frames

5.4.1 Beam Element Behaviour under Transverse Displacement

5.4.2 Frames with One Sway Degree of Freedom

5.4.3 Frames with Multi-sway Degrees of Freedom 139

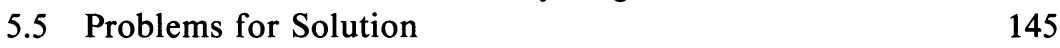

Reference $\quad 146$

Further Reading 146

6 The Matrix Stiffness Method-Part 2: Coordinate Transformation 147

6.1 The General Analysis of Trusses 148

$\begin{array}{ll}\text { 6.1.1 The Plane Truss Element } & 148\end{array}$

6.1.2 Coordinate Transformation for a Truss Element 150

6.1.3 Assembly of the Structure Stiffness Matrix using Truss Elements 152

6.1.4 Solution for Element Actions 154

6.2 The General Analysis of Plane Frames 155

6.2.1 The General Plane Frame Element 155

6.2.2 Coordinate Transformation for a Frame Element 157

6.2.3 Application of Boundary Conditions-Solution for Displacements 157

6.2.4 The Bandwidth of the Stiffness Matrix 171

6.2.5 Frame Elements with End Moment Releases 173

6.3 Composite Structures-Truss and Frame Elements 174

$\begin{array}{lll}6.4 & \text { Problems for Solution } & 179\end{array}$

$\begin{array}{ll}\text { Reference } & 182\end{array}$

Further Reading $\quad 182$

7 The Principle of Virtual Work 183

$\begin{array}{lll}7.1 & \text { Work Concepts } & 184\end{array}$

$\begin{array}{ll}\text { 7.2 The Principle of Virtual Displacements } & 185\end{array}$

7.2.1 The Principle of Virtual Displacements applied to a Rigid Body 185

7.2.2 The Principle of Virtual Displacements applied to a Deformable Body 191

7.2.3 A Mathematical Illustration of the Principle of Virtual Displacements

7.3 The Principle of Virtual Forces 196

7.3.1 General Application to the Deflection of Frames 198

7.3.2 General Application to the Deflection of Trusses 202

7.3.3 Deflection due to Temperature, Lack of Fit and Support Movements $\quad 204$

7.4 The Reciprocal Theorems 206 
7.5 Proof of the Relationship between the Statics Matrix and the Kinematics Matrix

7.6 Problems for Solution

References

Further Reading

8 The Flexibility Method of Analysis

8.1 Basic Concepts of the Flexibility Method

8.1.1 Analysis of Structures with One Degree of Statical Indeterminacy

8.1.2 Application to Higher-order Statically Indeterminate Structures

8.1.3 Deflection Calculations for Statically Indeterminate Frames

8.2 Matrix Formulation of the Flexibility Method

8.2.1 Forming the Flexibility Matrix

8.2.2 Analysis for Temperature and Support Movement

8.2.3 Element Flexibility Matrices

8.2.4 Fixed End Actions by Flexibility Analysis

9 The Approximate Analysis of Structures 245

9.1 Approximate Analysis of Beams and Rectangular Frames 246

9.1.1 Flexural Elements and Points of Inflection

9.1.2 Approximate Analysis of a Two-bay Rectangular Frame

9.1.3 Approximate Analysis of Multi-storey Rectangular Frames

9.2 Bounds on Solutions

9.3 Problems for Solution

10 Application of Computer Programs to Structural Analysis

10.1 The Structure of an Analysis Program

\subsubsection{Data Input}

10.1.2 Data Output

10.2 Modelling of Structures

10.2.1 Element Connections

10.2.2 Boundary Conditions

10.2.3 The Modelling of Non-skeletal Structures by Onedimensional Elements 
10.3 Influence of the Computer Program on Modelling 273

10.3.1 Additional Effects on Structures 274

10.3.2 The Use of Symmetry 277

$\begin{array}{ll}\text { References } & 278\end{array}$

Appendix A: MATOP (Matrix Operations Program)_User Manual 279

A.1 Introduction 279

A.2 Form of the Program 279

A.3 Operation of the Program 279

A.4 The Command Formats 280

A.5 An Example of the Use of the Program-Solution of Simultaneous Equations 282

A.6 Listing of the Program MATOP 283

Appendix B: Structural Mechanics Students' Handbook-A Manual of Useful Data and Information

Part 1

B1.1 Introduction-Convention 298

Table B1.1 Simple beam moments and deflections (uniform EI) 299

Table B1.2 Some properties of area 300

Table B1.3 Indeterminate beams end moments-transverse loads (uniform EI) 301

Table B1.3A Indeterminate beams end moments-translation only (uniform $E I$ )

Table B1.4 Beam end rotations under transverse load 303

Table B1.5 Standard integrals relating to moment diagrams 304

Table B1.6 Second moments of area 306

B1.2 Summary of the Slope-Deflection Equations 307

B1.3 Use of Table B1.4-Fixed End Moment Calculation 307

Part 2

B2.1 Introduction-Convention 308

B2.2 Continuous Beam Element 309

B2.3 Continuous Beam Element-LHE-pinned (Moment Release) 310

B2.4 Continuous Beam Element-RHE-pinned (Moment Release) 310

B2.5 Column Element 311

B2.6 Column Element-Base-pinned 311

B2.7 General Plane Frame Element 312

B2.8 Plane Grid Element 313

B2.9 Space Frame Element $\quad 314$

Reference $\quad 317$

$\begin{array}{ll}\text { Index } & 319\end{array}$ 


\section{List of Examples}

Example 2.1: Equilibrium Analysis of a Simple Bent 34

Example 2.2: Equilibrium Analysis of a Building Frame 35

Example 2.3: Equilibrium Analysis of a Truss 38

Example 3.1: Analysis of a Truss 53

Example 3.2: Deflections of a Cantilever Beam (1) 67

Example 4.1: Deflections of a Cantilever Beam (2) 79

Example 4.2: Analysis of a Continuous Beam 83

Example 4.3: Analysis of a Rectangular Plane Frame 94

Example 4.4: Frame Analysis using the Direct Stiffness Method 103

Example 4.5: Analysis of a Continuous Beam 109

Example 4.6: Analysis of a Non-swaying Rectangular Frame 114

Example 5.1: Moment Distribution of a Non-swaying Frame 132

Example 5.2: Moment Distribution of a Swaying Frame 136

Example 5.3: Moment Distribution of a Multi-storey Frame 141

Example 6.1: Analysis of a Continuous Beam 160

Example 6.2: Analysis of a Plane Frame 164

Example 6.3: Beam on an Elastic Foundation 177

Example 7.1: Reactions in an Indeterminate Frame 189

Example 7.2: Forces in an Indeterminate Truss 190

Example 7.3: Deflections in a Statically Determinate Frame 199

Example 7.4: Deflections in a Statically Determinate Truss 202

Example 8.1: Flexibility Analysis of a Tied Portal Frame 217

Example 8.2: Flexibility Analysis of a Higher-order Indeterminate

Frame 221

Example 8.3: Flexibility Analysis of a Higher-order Determinate Truss 223

Example 8.4: Deflection of a Statically Indeterminate Frame 226

Example 9.1: Beam Analysis 248

Example 9.2: Approximate Analysis of a Two-bay Frame 254

Example 9.3: Approximate Analysis of a Multi-storey Frame 257 


\section{Preface}

Significant changes have occurred in the approach to structural analysis over the last twenty years. These changes have been brought about by a more general understanding of the nature of the problem and the development of the digital computer. Almost all structural engineering offices throughout the world would now have access to some form of digital computer, ranging from hand-held programmable calculators through to the largest machines available. Powerful microcomputers are also widely available and many engineers and students have personal computers as a general aid to their work. Problems in structural analysis have now been formulated in such a way that the solution is available through the use of the computer, largely by what is known as matrix methods of structural analysis. It is interesting to note that such methods do not put forward new theories in structural analysis, rather they are a restatement of classical theory in a manner that can be directly related to the computer.

This book begins with the premise that most structural analysis will be done on a computer. This is not to say that a fundamental understanding of structural behaviour is not presented or that only computer-based techniques are given. Indeed, the reverse is true. Understanding structural behaviour is an underlying theme and many solution techniques suitable for hand computation, such as moment distribution, are retained. The most widely used method of computer-based structural analysis is the matrix stiffness method. For this reason, all of the fundamental concepts of structures and structural behaviour are presented against the background of the matrix stiffness method. The result is that the student is naturally introduced to the use of the computer in structural analysis, and neither matrix methods nor the computer are treated as an addendum.

Matrix algebra is now well taught in undergraduate mathematics courses and it is assumed that the reader is well acquainted with the subject. 
In many instances the solution techniques require the manipulation of matrices and the solution of systems of simultaneous linear equations. These are the operations that the digital computer can most readily handle and they are operations which are built into computer application programs in structural engineering. For the student, however, it is important that these operations are understood, so that it is desirable to have a form of matrix manipulation computer program available. Many programmable pocket calculators currently provide for such operations and there is no doubt that the capacity and speed with which these machines can carry out these tasks will increase with further developments. Some computer languages, notably some versions of BASIC, provide for general matrix manipulation, and scientific library subroutines for handling matrices are provided with other languages such as Fortran. A third possibility is to provide a computer program in the form of a problem-orientated language, with a command structure directly aimed at facilitating the manipulation of matrices. Such a computer program, known as MATOP and developed by the author, is presented as an appendix to the text and used with illustrative examples throughout. The program is not unique and other such programs have been widely available for a number of years.

The text is seen as a first course in structural mechanics or the theory of structures, although it is assumed that students will have done a first course in the more general field of applied mechanics including simple beam theory and stress analysis. The material is probably more than can be covered in two semesters, and indeed it has been delivered over three semesters. The first two chapters outline the fundamental principles and introduce students to the nature of structures and the structural analysis problem. A detailed study of equilibrium and statical and kinematic determinacy is presented in chapter 2 . In chapter 3 , the foundations of the matrix stiffness method are presented and the ideas of element and structure stiffness matrices are developed. The classical slope-deflection equations are developed from simple beam theory in this chapter, and presented in matrix notation to give the general beam element stiffness matrix.

The matrix stiffness method is further developed in chapter 4 , where it is applied to continuous beams and rectangular frames. At this stage coordinate transformation is not introduced and axial deformation of the element is ignored. The approach leads to some powerful applications where the analysis results can be obtained quite rapidly, particularly with the use of the direct stiffness method. It is shown in many instances that the solution is reduced to one of handling matrices of a size that can be adequately dealt with on a pocket calculator.

The moment distribution method has been retained as a useful hand method of analysis and this is detailed in chapter 5, with applications to beams and rectangular frames. The work is closely related to that of chapter 4 and the moment distribution method is shown as a logical variation of 
the matrix stiffness method. Chapter 6 returns to the matrix stiffness method to introduce the general stiffness method and coordinate transformation. A wider range of structures is now considered, including composite structures where elements of different types are introduced into the one structure.

A fundamental study of structural analysis must include a reference to the principle of virtual work which is presented in chapter 7 . Both the principle of virtual displacements and the principle of virtual forces are considered. The principle of virtual forces, particularly with regard to expressions for the deflection of structures, leads logically into the flexibility method of analysis presented in chapter 8 . This provides an alternative approach to the stiffness method and gives a balance to the overall study.

The author is convinced that the general use of computer programs for structural analysis makes demands for greater, rather than less, awareness and understanding of structural behaviour on the part of users. Structural computations must still be checked, results must still be interpreted and engineering judgement must still be exercised. To facilitate this, a chapter on approximate methods of analysis is included (chapter 9). It is presented at this stage since it is felt that approximate methods can only be introduced against a background of general knowledge of structural behaviour.

In a final chapter, some general guidance to computer application programs in structural analysis is presented. Some aspects of modelling of structures are also discussed. Numerous examples are given throughout the text and a common thread is achieved through the use of the program MATOP, details of which are given in an appendix with a program listing in Fortran 77. Much of the data presented throughout the text is collected together in another appendix as a 'Structural Mechanics Students' Handbook'. The significant data here is a collective statement of the element stiffness matrices for various element types.

W. J. Spencer 